\title{
Examination of parameters used in ant colony algorithm over truss optimization
}

\author{
Abidin Hakan YILMAZ, Zekeriya AYDIN* \\ Tekirdağ Namık Kemal University, Faculty of Çorlu Engineering, \\ Department of Civil Engineeering, Çorlu, Tekirdağ. \\ Geliş Tarihi (Received Date): 01.07.2021 \\ Kabul Tarihi (Accepted Date): 04.11.2021
}

\begin{abstract}
Metaheuristic optimization techniques have been used to solve engineering problems with an increasing speed for the last 30 years. Most of these algorithms have been developed by imitating a process in nature. In this study, the ant colony algorithm inspired by the natural life of ants is discussed. The ant colony algorithm requires some parameters to perform an optimization, as in other meta-heuristic algorithms. The aim of this study is to examine the effect the values of the parameters used in the ant colony algorithm on the results. For this purpose, as an exemplary problem, a study was carried out on the optimization of truss systems, one of the constrained problems frequently discussed in the literature. Appropriate values of optimum design parameters such as number of ants, pheromone update coefficient and penalty coefficient were investigated using the coded computer program. As a result of the study, the effect of the relevant parameters on the result was determined and the points to be considered in the selection of these parameters were specified.
\end{abstract}

Keywords: Metaheuristic algorithms, ant colony algorithm, optimization parameters, trusses

\section{Karınca koloni algoritmasında kullanılan parametrelerin kafes sistem optimizasyonu üzerinden irdelenmesi}

$\ddot{\mathbf{O} z}$

Meta-sezgisel optimizasyon teknikleri son 30 yıldır giderek artan bir hızla mühendislik problemlerinin çözümünde kullanılmaktadır. Bu algoritmaların çoğu doğadaki bir

Abidin Hakan YILMAZ, abidinhakanyilmaz@gmail.com, https://orcid.org/0000-0001-7476-4685

*Zekeriya AYDIN, zaydin@nku.edu.tr, http://orcid.org/0000-0003-1597-998X 
süreci taklit ederek geliştirilmiştir. Bu çalışmada karıncaların doğal yaşamını taklit ederek geliştirilmiş karınca koloni algoritması ele alınmıştır. Diğer meta-sezgisel algoritmalarda olduğu gibi karınca koloni algoritması da bir optimizasyonu gerçekleştirebilmek için bir takım parametrelere ihtiyaç duymaktadır. Bu çalışmanın amacı karınca koloni algoritmasında kullanılan parametrelerin değerlerinin sonuçlara etkisini irdelemektir. Bu amaç doğrultusunda örnek problem olarak, literatürde çok sık ele alınan sinirlayıcil problemlerden biri olan kafes sistemlerin optimizasyonu üzerinden çalışma gerçekleştirilmiştir. Çalışmada kodlanan bir bilgisayar programı ile karınca sayıs, feromon güncelleme katsayıs ve ceza katsayıs gibi optimum tasarım parametrelerinin uygun değerleri araştırılmıştır. Çalışma sonucunda ilgili parametrelerin sonuca etkisi belirlenmiş ve bu parametrelerin seçiminde dikkat edilecek hususlar belirtilmiştir.

Anahtar kelimeler: Meta-sezgisel algoritmalar, karınca koloni algoritmasl, optimizasyon parametreleri, kafes sistemler

\section{Introduction}

Many different solutions can be obtained in civil engineering studies depending on architectural and structural criteria. The main purpose of a project engineer is to obtain the most suitable solution among these solutions. However, to find the most suitable solution from the infinite solution space, it is necessary to make many repetitive calculations and spend a lot of time. Besides, the quality of the solution and the time to reach it may vary according to the designer's knowledge and experience. The rapidly increasing population and growing industry around the world caused the need for a large number of various structures and for human resources in the field of construction and structural engineering [1].

The increase in the criteria and the size of the problem in the structures makes classical optimization methods inadequate. This and many other reasons led the designers to different searches and solving completely natural life by modeling, as in many disciplines, in order to get faster and more appropriate results from optimization studies. Natural models such as the human brain, evolution theory, and colonial behavior are expressed mathematically and successfully applied in solving optimization problems [1].

Ant colony optimization, one of the metaheuristic methods, has been successfully applied in different problems since 1991 [2]. A modified version of the ant colony method is used in this study. The study aims to examine the effect of parameters used in the ant colony optimization algorithm on the results obtained. Within this scope, the optimum values of the parameters such as the number of ants, the pheromone update coefficient, and the penalty coefficient were investigated on a truss example that is widely handled in the literature. The objective function is the structure weight, and the design variables are the bar cross-section areas. Strength and slenderness are calculated according to AISC-ASD (American Institute of Steel Construction-Allowable Stress Design) [3], and displacement limitation is also taken into consideration. A computer program is coded to make the necessary calculations for optimization and structural design. Ant colony algorithm is an alternative optimization method for all disciplines. Since the starting point was the traveling salesman problem, it is used widely in areas of 
logistics, industrial engineering, and transportation engineering. However, it is also used in problems in the field of structural engineering. It has been seen that it gives more suitable results than other optimization methods in some studies and it is also used in combination with other optimization techniques. Some of the studies using the ACO algorithm are briefly mentioned below. Bland [4] is one of the first researchers to use the ant colony method for optimum design of structures. In that study, ant colony optimization method and tabu search (ACOTS) method were hybridized and used together. Camp and Bichon [5] worked on the optimization of 10-bar plane truss, 25 and 72 bar space truss systems using discrete design variables. After this study, Camp et al. [6] studied on the shape optimization of plane trusses using discrete design variables. Serra and Venini [7] worked on the optimization of the 6-bar and 10-bar plane truss system. They stated that the ant colony method is a successful randomness method in solving design problems and is more developable than other methods. Kaveh et al. [8] worked on the shape optimization of plane and space truss systems using the ant colony algorithm. Aydoğdu [9] studied the optimization of space trusses under the effect of distortion caused by torsion with ant colony optimization and Harmony Search methods, and compared these two methods on six different optimization problems. Yoo and Han [10] studied on topological optimization using an improved ant colony optimization algorithm. Babaei and Sanaei [11] discussed the optimization of braced frame systems using an ant colony algorithm hybridized with the genetic algorithm. Kalatjari and Talebpour [12] optimized skeletal structures using an improved ant colony optimization algorithm. Shafei and Shirzad [13] conducted a dynamic stability study of laminated composite plates using an ant colony optimization algorithm. Liu et al. [14] utilized a modified ant colony optimization algorithm for topographical design of stiffener layout for plates against blast loading. Greco et al. [15] proposed a modified ant colony system to the evaluation of the plastic load and failure modes of planar frames. $\mathrm{Li}$ and $\mathrm{He}[16]$ studied on the optimization of the construction project using an improved ant colony algorithm. Soheili et al. [17] used ant colony optimization algorithm to obtain the best settings for tuned mass dampers values on a 40-story building.

\section{Optimization of trusses}

There are many studies in the literature on the optimization of trusses handled previously; most of these studies are realized using a meta-heuristic optimization algorithm [18-25]. Like on the previous studies, to identify a truss optimization problem, objective function, design variables and constraints must be defined. These characteristics of the problem conducted in this study are explained below.

\subsection{Objective function}

The most important optimization criterion considered in the design problems of steel structures is the weight of the structure. Other factors affecting the cost of a steel structure are installation work, maintenance of the structure and formation of the joints. If all factors that will affect the cost of the steel structure are classified as material and labor, the minimum cost can be given as in the following equation.

$$
\mathrm{C}_{\mathrm{s}}=\mathrm{f}\left(\mathrm{P}_{\mathrm{m}}, \mathrm{P}_{1}\right)
$$

where, $\mathrm{C}_{\mathrm{s}}$ is the cost function, $\mathrm{P}_{\mathrm{m}}$ and $\mathrm{P}_{1}$ are the material and labor cost of the related steel structure, respectively. In this study, optimum design of truss structures has been 
realized and only the minimum weight has been taken into account in the objective function. Therefore, the objective function, W, can be expressed as follows.

$$
\mathrm{W}=\rho \sum_{\mathrm{i}=1}^{\mathrm{nm}} \mathrm{L}_{\mathrm{i}} \mathrm{A}_{\mathrm{i}}
$$

In this equation, $\rho$ is the unit weight of the material, $L_{i}$ and $A_{i}$ are the length and crosssection area of the $\mathrm{i}^{\text {th }}$ bar, respectively, and $\mathrm{nm}$ is the total number of members in the system [1].

In this study, members of the trusses are grouped in some examples. By showing this grouping on the objective function, the formulation of the objective function can be given as follows.

$$
\mathrm{W}=\rho \sum_{\mathrm{k}=1}^{\mathrm{ng}} \mathrm{A}_{\mathrm{k}} \sum_{\mathrm{i}=1}^{\mathrm{nm}} \mathrm{L}_{\mathrm{i}}
$$

where $A_{k}$ shows the cross-sectional area of the elements belonging to the group $\mathrm{k}, \mathrm{ng}$ shows the total number of groups in the problem [1]

\subsection{Design variables and design parameters}

In this study, size optimization of trusses is conducted, and the bar cross-section areas are taken into account as design variables. In trusses, the cross-sectional area of each bar can be evaluated as a separate design variable, or grouping can be made for bars with the same or similar functions. As mentioned before, in some examples, element grouping is considered. In this case, the number of design variables in the truss system will be equal to the number of groups. Discrete design variables are used in the study. Therefore, the possible values of the design variables (design variables value set) are determined before the optimization process [1].

Design parameters are structural features that are effective in the calculation of the objective function and whose value does not change during the optimization process, unlike design variables. The dimensions, topology, loads, and material properties of the truss system are the essential design parameters in the size optimization of a truss structure.

\subsection{Constraints}

While designing a steel structure, some limits should not be exceeded in order to make the structure usable. Therefore, in this study, the strength, slenderness, and displacement constraints are considered. The strength and slenderness constraints are calculated according to AISC-ASD [3].

\subsubsection{Strength constraint}

In order to ensure that the truss has sufficient strength, the strength constraint $\left(g_{1}\right)$ is calculated as follows depending on the stress limitation of each bar.

$\mathrm{g}_{1}=\sum_{\mathrm{i}=1}^{\mathrm{nm}} \mathrm{g}_{1, \mathrm{i}}$ 
In this equation, $\mathrm{g}_{1, \mathrm{i}}$ is the stress limitation for the $\mathrm{i}^{\text {th }}$ member and it is calculated in normalized form as

$$
\left.\begin{array}{llll}
\mathrm{g}_{1, \mathrm{i}}=\frac{\sigma_{\mathrm{i}}}{\sigma_{\mathrm{a}, \mathrm{i}}}-1 & \text { if } & \sigma_{\mathrm{i}}>\sigma_{\mathrm{a}, \mathrm{i}} \\
\mathrm{g}_{1, \mathrm{i}}=0 & \text { if } & \sigma_{\mathrm{i}} \leq \sigma_{\mathrm{a}, \mathrm{i}}
\end{array}\right\}
$$

where $\sigma_{\mathrm{i}}$ is the stress calculated for the $\mathrm{i}^{\text {th }}$ member, $\sigma_{\mathrm{a}, \mathrm{i}}$ is the allowable stress for the $\mathrm{i}^{\text {th }}$ bar. The allowable stress is calculated by Equations (6) and (7) for tension and compression members, respectively.

$$
\left.\begin{array}{rl}
\sigma_{\mathrm{a}, \mathrm{i}}= & 0.6 \cdot \mathrm{F}_{\mathrm{y}} \\
\sigma_{\mathrm{a}, \mathrm{i}}= & \frac{\left[1-\frac{\lambda_{\mathrm{i}}{ }^{2}}{2 \cdot \mathrm{C}_{\mathrm{c}}{ }^{2}}\right] \cdot \mathrm{F}_{\mathrm{y}}}{\frac{5}{3}+\frac{3 \cdot \lambda_{\mathrm{i}}}{8 \cdot \mathrm{C}_{\mathrm{c}}}-\frac{\lambda_{\mathrm{i}}{ }^{3}}{8 \cdot \mathrm{C}_{\mathrm{c}}{ }^{3}}} \text { if } \lambda_{\mathrm{i}}<\mathrm{C}_{\mathrm{c}} \\
\sigma_{\mathrm{a}, \mathrm{i}} & =\frac{12 \cdot \pi^{2} \cdot \mathrm{E}}{23 \cdot \lambda_{\mathrm{i}}{ }^{2}} \quad \text { if } \lambda_{\mathrm{i}}>\mathrm{C}_{\mathrm{c}}
\end{array}\right\}
$$

In the equations given above, $\mathrm{F}_{\mathrm{y}}$ is the yield stress of the material, $\mathrm{E}$ is the modulus of elasticity, $\lambda_{i}$ is the slenderness of the $i^{\text {th }}$ member, $C_{c}$ is the plastic slenderness limitation which calculated as follows.

$C_{c}=\sqrt{\frac{2 \cdot \pi^{2} \cdot E}{F_{y}}}$

\subsubsection{Slenderness constraint}

The slenderness constraint $\left(\mathrm{g}_{2}\right)$ is calculated with the following equation depending on the violation of the slenderness limitation of each bar.

$$
\mathrm{g}_{2}=\sum_{\mathrm{i}=1}^{\mathrm{nm}} \mathrm{g}_{2, \mathrm{i}}
$$

In this equation, $\mathrm{g}_{2, \mathrm{i}}$ represents the value of the slenderness limiter for the $\mathrm{i}^{\text {th }}$ bar and can be calculated in normalized form by the following equation.

$$
\left.\begin{array}{llll}
\mathrm{g}_{1, \mathrm{i}}=\frac{\lambda_{\mathrm{i}}}{\lambda_{\lim }}-1 & \text { if } & \lambda_{\mathrm{i}}>\lambda_{\lim } \\
\mathrm{g}_{1, \mathrm{i}}=0 & \text { if } & \lambda_{\mathrm{i}} \leq \lambda_{\lim }
\end{array}\right\}
$$

In the above equation, $\lambda_{\lim }$ represents the limit of slenderness, and $\lambda_{\lim }=200$ for pressure rods and $\lambda_{\lim }=300$ for tension rods. $\lambda_{\mathrm{i}}$ is the slenderness ratio of the $\mathrm{i}^{\text {th }}$ bar and calculated as 
$\lambda_{\mathrm{i}}=\frac{\mathrm{K}_{\mathrm{i}} \mathrm{L}_{\mathrm{i}}}{\mathrm{r}_{\mathrm{i}}}$

where $K_{i}$ and $r_{i}$ represent the buckling coefficient for the bar $i$ and the radius of gyration of the bar cross-section, respectively.

\subsubsection{Displacement constraint}

The constraint, $g_{3}$, to ensure that the displacements that will occur at the joints of the truss remain within the defined limits, is expressed as follows depending on the displacement limiter of each point.

$\mathrm{g}_{3}=\sum_{\mathrm{i}=1}^{\mathrm{np}} \mathrm{g}_{3, \mathrm{i}}$

In this equation, $\mathrm{np}$ indicates the number of joints in the truss, $\mathrm{g}_{3, \mathrm{i}}$ is the displacement limiter for the $\mathrm{i}^{\text {th }}$ bar, and it is calculated in normalized form as

$\left.\begin{array}{lll}g_{3, i}=\frac{f_{i}}{f_{a, i}}-1 & \text { if } \quad f_{i}>f_{a, i} \\ g_{3, i}=0 & \text { if } & f_{i} \leq f_{a, i}\end{array}\right\}$

where $f_{i}$ and $f_{a, i}$ are the resulting displacement and allowable displacement values for the joint $\mathrm{i}$, respectively.

\subsection{Penalized objective function}

The optimum design problem defined up to this section uses some constraints. However, since most of the meta-heuristic algorithms are developed for unconstrained optimization problems, the optimization problem determined depending on the constraints should be transformed into an unconstrained form. For this transformation, a penalty function is determined depending on the degree of violation of the constraints. In this study, the penalty function (C) is calculated with the following equation depending on the strength, slenderness and displacement constraints.

$\mathrm{C}=\mathrm{g}_{1}+\mathrm{g}_{2}+\mathrm{g}_{3}$

By adding the penalty function to the objective function, the objective function is converted to the penalized objective function that includes the constraints. There are various approaches to the establishment of the penalized objective function in the literature. In this study, the penalized objective function, $\Phi$, is calculated using the following equation [26].

$\Phi=\mathrm{W} \cdot[1+\mathrm{K} \cdot \mathrm{C}]$

In this equation, $\mathrm{K}$ is the penalty coefficient, which determines the effect of the constraints on the solution, and its value is determined according to the problem. 


\section{Ant colony optimization algorithm}

Ant Colony Optimization algorithm is based on mathematical modeling of the foraging strategies of real ant colonies. The first ant colony algorithm was applied to the Traveling Salesman Problem by Dorigo [2]. In that study, ant colony algorithm was applied to many traveling salesman problems of different sizes, but it was observed that the success rate decreased as the scale of the problem increased, while it was successful in problems with less than 75 cities.

\subsection{The behavior of natural ant colonies}

Despite being inadequate individually, ants have the ability to find and to carry the food to the nest, and to do this in the shortest time possible by acting as a colony. In the nestfood-nest cycle of the ants, the ant that follows the shortest path will be the fastest returning ant. The chemical pheromone substance, which reveals the ability of ants to follow each other, is effective at this stage. Pheromone is the scent ants leave in their paths while they are in motion, and this scent becomes a pheromone pathway that shows the trail of ants. Trailing ants are more likely to follow the pheromone-dense path than the less pheromone-concentrated path. However, it is also possible that the path with low pheromone concentration or a path with no pheromone is chosen by other ants (Figure 1).
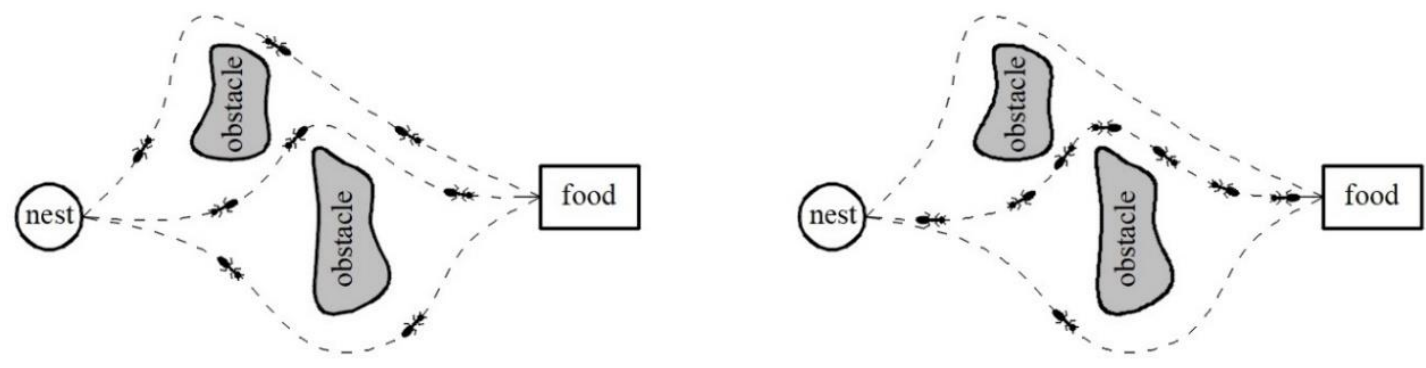

Figure 1. Route selection of the ant colony

The behavior of the ants towards different amounts and densities of pheromones in varying time intervals was investigated, and it was observed that the pheromones were dependent on factors such as evaporation rate, absorption rate and diffusion constant. The duration of action of pheromones can last from a few hours to a few months, depending on the ant species, colony size and enzyme structure.

\subsection{Optimization algorithm}

In this study, a simplified ant colony optimization algorithm is used compared to the algorithms in the literature. The simplification means that the results are achieved with much shorter and fewer operations compared to other ant colony algorithms used in the literature, as explained below [1].

In natural ant behavior, when an ant colony begins to forage, there is no pheromone at the beginning on the route between the nest and the food source. This is the case in many ant colony algorithms used in the literature. However, in the ant colony algorithm to be used in this study, it will be accepted that there are some pheromones in the ways that represent possible solutions to the problem at the beginning of the research. Since no information was initially known about the optimum solution, it would be considered 
that there is an equal amount of pheromone in each of the selected values for each design variable. These initial pheromone amounts can be calculated with the following equation for the $\mathrm{j}^{\text {th }}$ value of the $\mathrm{i}^{\text {th }}$ design variable.

$$
\mathrm{P}_{\mathrm{ij}}^{1}=\frac{1}{\mathrm{nv}_{\mathrm{i}}}
$$

In this equation, $\mathrm{nv}_{\mathrm{i}}$ denotes the number of values in the set of values selected for the $\mathrm{i}^{\text {th }}$ design variable. Thus, the sum of the pheromone amounts for the values of each design variable will be equal to "1" and this value will not change during the optimization process [27].

The amount of pheromone calculated by the above equation should be increased for the values followed by the best solution in each iteration, while decreasing for other values. This process is called pheromone updating as mentioned before. As a result of the pheromone update, the new pheromone amounts, $P_{i j}{ }^{k}$, will be calculated with the following equations for the $\mathrm{j}^{\text {th }}$ value of the $\mathrm{i}^{\text {th }}$ design variable in the $\mathrm{k}^{\text {th }}$ iteration.

$$
\left.\begin{array}{l}
P_{i j}^{k}=P_{i j}^{k-1} \cdot\left(1-\frac{F \cdot n v_{i}}{n v_{i}-1}\right) \text { if } j \neq V_{i}^{k} \\
P_{i j}^{k}=\frac{1-P_{i j}^{k-1}}{P_{i j}^{k-1}} \cdot \frac{F \cdot n v_{i}}{n v_{i}-1} \text { if } j=V_{i}^{k}
\end{array}\right\}
$$

The amount of pheromone used by the best solution is increased with the second of the above equations, while the first one decreases the pheromone amount of the others. In these equations, $\mathrm{V}_{\mathrm{i}}^{\mathrm{k}}$ expresses the sequence number of the value of the $\mathrm{i}^{\text {th }}$ design variable for the best solution in the $\mathrm{k}^{\text {th }}$ iteration, $\mathrm{F}$ is called the pheromone update coefficient, which is a coefficient that determines how much pheromone will be released to the design variable values of the best solution. The best value of the pheromone update coefficient may vary depending on the problem, and this value can be found by trial and error based on experience. A review is presented in this study to determine the pheromone update coefficient and the number of ants [1,27].

In the ant colony algorithm, the pheromone amounts of the design variable values, which are not followed by the best solution, decrease. This situation is similar to the evaporation of the amount of pheromones in the less preferred routes between the nest and the food source in natural ant colony behavior.

\section{Investigation the impact of optimization parameters}

In this section, how the values of some parameters used in the ant colony optimization algorithm affect the results will be examined. The parameters to be considered are the number of ants, the pheromone update coefficient, the penalty coefficient, and the number of values in the set selected for the values of the design variables. By changing the values of these parameters, the value of the penalized objective function, the number of iterations and he solution time will be examined. A 10-bar plane truss system, which is one of the most studied problems in the literature, was chosen to carry out these 
studies. The truss system is shown in Figure 2, the unit of measurement in this figure is meter. For this example, 360 optimizations were made with different data and the results obtained with the parameters used were examined and shown in graphs.

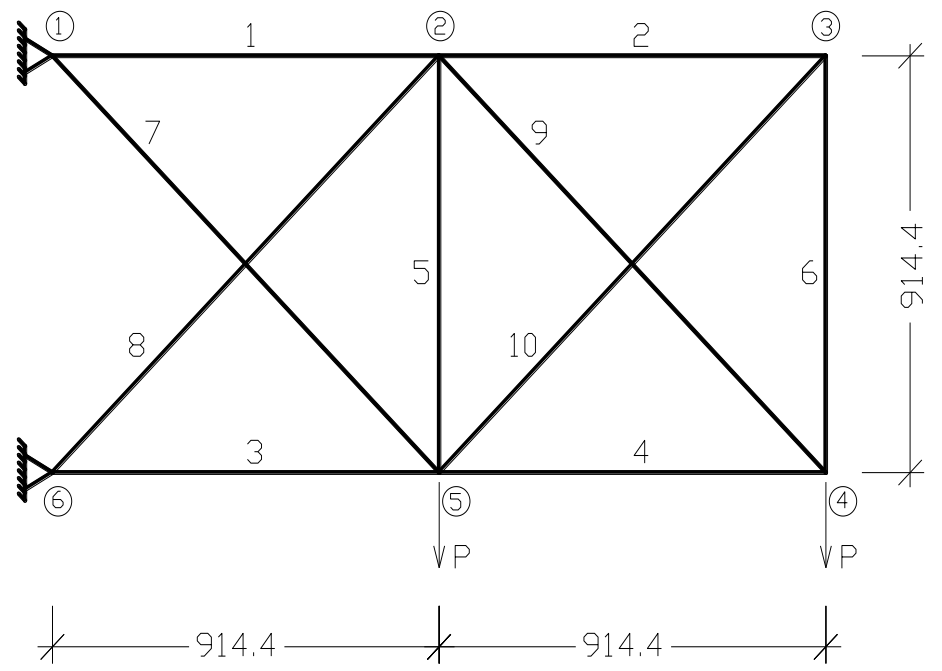

Figure 2. Ten-bar plane truss

In this example, material properties are: the unit weight $\rho=7.85 \mathrm{t} / \mathrm{m}^{3}$, elasticity modulus $E=20 \cdot 10^{6} \mathrm{t} / \mathrm{m}^{2}$, yield strength $\mathrm{Fy}=24000 \mathrm{t} / \mathrm{m}^{2}$. The displacement limit of all points is $\pm 0.0508 \mathrm{~m}$ in both directions. Strength and slenderness constraints are also considered in this example in accordance with the AISC-ASD [3] as described in Section 2.3. $\mathrm{P}=44.5 \mathrm{t}$ of load is considered on joints 4 and 5 as shown in the figure. In this example, the bars are not grouped and there are a total of ten design variables. For these design variables, 200 pipe sections are selected from the list of DIN 2448 and these sections are shown in Table 1.

\subsection{Examination the penalty coefficient}

As mentioned before, the penalty function is added to the objective function by multiplying it by a coefficient in order to transform to the constrained optimization problem into an unconstrained form. This coefficient is called the penalty coefficient and determines how the constraints will affect the objective function. Therefore, it is essential to determine the penalty coefficient effectively in order to reach the optimum result in a short time.

In order to determine the effect of the penalty coefficient on the results, ten-bar truss is optimized by using seven different values $(1.0,1.5,2.0,2.5,3.0,3.5$ and 4.0) of the penalty coefficient. A total of 21 optimizations are performed for each penalty coefficient using colonies of 5, 10, 20, 30, 40, 50, 100, 200, 300, 400, 500, 600, 700, $800,900,1000,1500,2000,3000,4000$, and 5000 ants. The pheromone update coefficient is taken as 0.025 in the optimizations made to determine the penalty coefficient.

The best and the average values of penalized objective function, the average of the number of iterations required for the optimization process, and the average of time required for the optimization procedure are given, respectively, in Figure 3, Figure 4 and Figure 5, depending on the different values of the penalty coefficient. 
Table 1. Cross-sectional area (A) and radius of gyration (r) of 200 pipe sections

\begin{tabular}{|c|c|c|c|c|c|c|c|c|c|c|c|c|c|c|}
\hline No & $\underset{\left(\mathbf{c m}^{2}\right)}{\mathbf{A}}$ & $\begin{array}{c}\mathbf{r} \\
(\mathbf{c m})\end{array}$ & To & $\underset{\left(\mathbf{c m}^{2}\right)}{\mathbf{A}}$ & $\begin{array}{c}\mathbf{r} \\
(\mathbf{c m})\end{array}$ & S & $\underset{\left(\mathbf{c m}^{2}\right)}{\mathbf{A}}$ & (cm) & No & $\underset{\left(\mathbf{c m}^{2}\right)}{\mathbf{A}}$ & $\begin{array}{c}\mathbf{r} \\
(\mathbf{c m})\end{array}$ & No & $\underset{\left(\mathbf{c m}^{2}\right)}{\mathbf{A}}$ & $\begin{array}{c}\mathbf{r} \\
(\mathbf{c m})\end{array}$ \\
\hline 1 & 1088 & 167 & & 73 & 575 & 21 & & & 121 & 38.090 & 6.040 & 161 & 82.657 & 9.305 \\
\hline 2 & 0 & 45 & & & & 32 & & & 122 & 3 & 010 & 62 & & $2 / 1$ \\
\hline 3 & .733 & 127 & & & & 83 & & .214 & 123 & 46.741 & .983 & 163 & & 9.221 \\
\hline 4 & .18 & 42 & & & 4 & 84 & & 194 & 124 & 7 & .943 & & & .164 \\
\hline 5 & .896 & 400 & & & 317 & 85 & & 170 & 125 & 57.665 & .910 & 165 & 129.23 & 9.104 \\
\hline 6 & & & & & & 86 & & & & & & & & 1000 \\
\hline 7 & .087 & 350 & & 3800 & 273 & 87 & 6306 & 113 & 127 & 73.012 & .806 & 167 & 79.426 & 1172 \\
\hline 8 & & & & & & 88 & & & & & & & & ats \\
\hline 9 & .666 & 296 & & 9.920 & 217 & 89 & 1754 & 047 & 129 & 33.106 & 6.653 & 169 & 98.654 & 1104 \\
\hline 10 & .789 & 258 & & & & 90 & & & 130 & & 629 & 70 & & 1070 \\
\hline 11 & 1.322 & & & 6.771 & 152 & 01 & & 966 & 131 & & .602 & 171 & & 1010 \\
\hline 12 & .004 & 181 & 5 & & & 92 & & & 132 & & .572 & 172 & & 0.961 \\
\hline 13 & .005 & 121 & & 4.982 & 072 & $0 ?$ & & 856 & 133 & & 545 & 173 & & 0.70 \\
\hline 14 & .045 & & & & & 94 & & & 134 & & & 74 & & 2.29 \\
\hline 15 & 812 & & & & & 05 & & 448 & 135 & & 471 & 175 & & 2265 \\
\hline 16 & .074 & 680 & & & & 9 & & & 136 & & & 6 & & 2.22 \\
\hline 17 & & 662 & & & & & & & 137 & & .366 & & & $12.1 \%$ \\
\hline 18 & .186 & 646 & & & & 98 & & 376 & 138 & & & 78 & & 12.13 \\
\hline 19 & & 626 & & & & & & & 139 & & & & & ק \\
\hline 20 & 137 & 603 & & & 485 & & & & 140 & & 500 & 80 & & 12.02 \\
\hline 21 & & $5 / 0$ & & & & & & & 141 & & & & & 1406 \\
\hline 22 & 143 & 447 & & & 428 & & & 247 & 142 & & & & & 14.019 \\
\hline 23 & & & & & & & & & 143 & & & & & \\
\hline 24 & .800 & 483 & & & 363 & & & 144 & 144 & & 68 & 84 & & 13.933 \\
\hline 25 & & & & & & & & & & & & & & \\
\hline 26 & 518 & 405 & & & 283 & & & 793 & 146 & 91.444 & .262 & 86 & 196.32 & 13.814 \\
\hline 27 & & & & & & & & & & & & & & 15.00 \\
\hline 28 & 6.263 & 302 & & 58.834 & .175 & & 8.635 & .756 & 148 & 47.164 & 3.425 & 188 & 154.19 & 15.773 \\
\hline 29 & & & & & & & & & & & & & & 10.122 \\
\hline 30 & .866 & 902 & & .121 & 783 & & 71 & 705 & 150 & 59.463 & 366 & 190 & 197.62 & 15.663 \\
\hline 31 & & $00 \mathrm{~J}$ & & & & & & & 151 & & & & & 15.002 \\
\hline 32 & .176 & 868 & & 3.602 & .745 & & 13 & 5.648 & 152 & 73.700 & 8.298 & 192 & 171.82 & 17.576 \\
\hline 33 & & (070 & & & .122 & & & & 153 & & & & & 11.524 \\
\hline 34 & . 384 & 825 & & 589 & 695 & & 54 & 575 & 154 & 91.143 & 8.214 & 194 & 220.38 & 17.466 \\
\hline 35 & .921 & 3.198 & & & 4.665 & & & & 155 & 102.78 & & & 24 & 17.404 \\
\hline 36 & 26.727 & 3760 & 76 & 36.203 & 4.638 & & 68.773 & 5.471 & 156 & 114.90 & 8.098 & 196 & 214.70 & 19.327 \\
\hline 37 & .178 & 3.143 & 1 & 40.763 & 4.599 & 17 & & 5.414 & 157 & 52.807 & 9.432 & 197 & 243.14 & 19.268 \\
\hline 38 & 32.780 & 3704 & 10 & 44.493 & 4.567 & & 27.154 & 6.112 & 158 & 59.334 & 9.404 & 198 & 273.05 & 19.206 \\
\hline 39 & 5.712 & 673 & 19 & 49.971 & 4.519 & 119 & 30.307 & 6.091 & 159 & 66.629 & 9.373 & 199 & 265.90 & 21.071 \\
\hline 40 & & & 8 & 56.009 & 4.465 & & & 6.068 & 160 & 73.070 & 9.346 & 200 & 298.70 & 21.009 \\
\hline
\end{tabular}




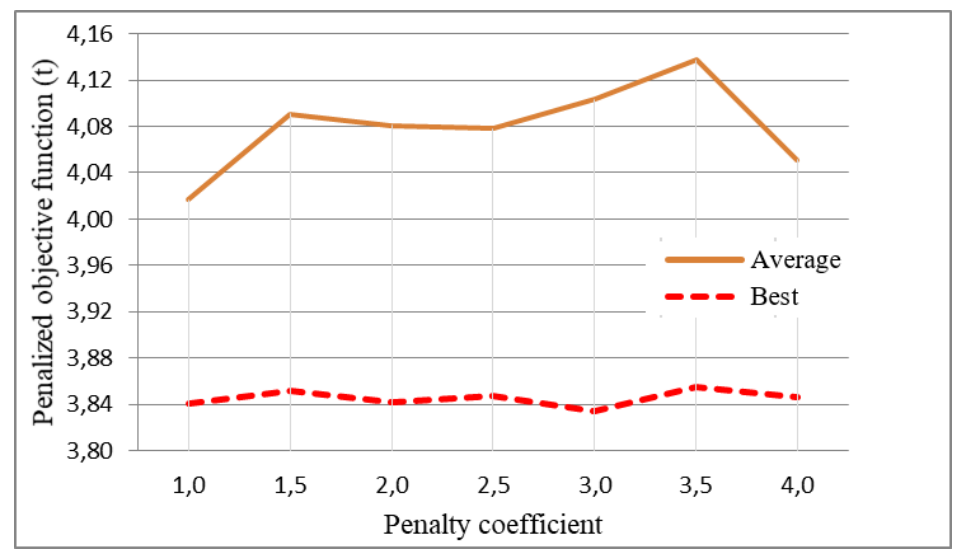

Figure 3. The penalized objective function versus the penalty coefficient

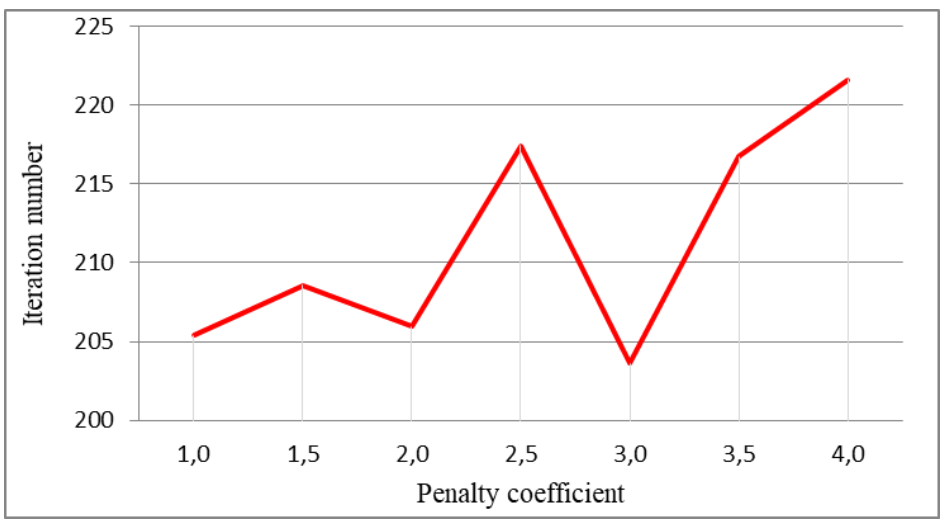

Figure 4. Average of the iteration number versus the penalty coefficient

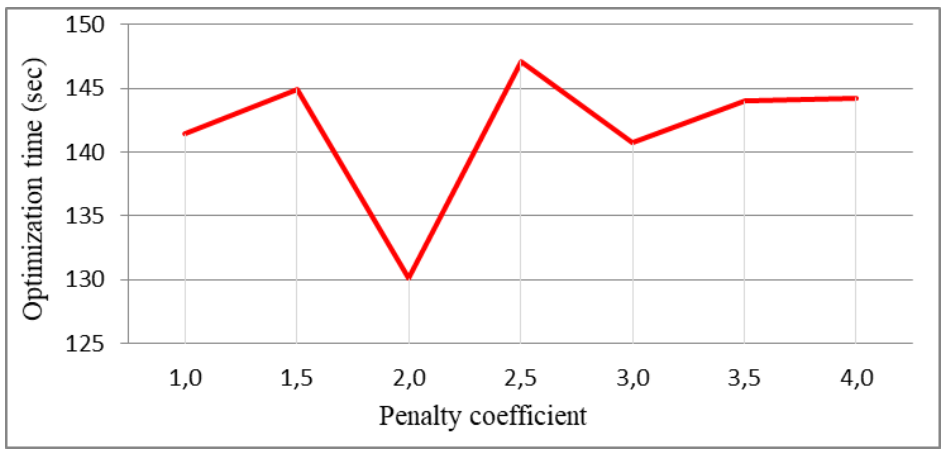

Figure 5. Average of optimization time versus the penalty coefficient

From Figure 3, the best solutions reached for each penalty coefficient were found with different ant numbers. There is no exact trend to a good solution depending on the increase or decrease in the penalty coefficient. Although the best penalty coefficient for average values seems to be 1.0 , since the aim in optimization is to find the best solution, it is seen from the best values curve that this result is reached by taking the penalty coefficient 3.0. Thus, while investigating the pheromone update coefficient in the next section, the penalty coefficient will be taken as 3.0 in all solutions. Figure 4 shows that as the penalty coefficient increases, the mean of the number of iterations tends to increase, although it is not linear. However, the lowest iteration average value is reached for the penalty coefficient 3.0. From the graph given in Figure 5, it is seen that the 
optimization time can vary by $13 \%$ depending on the penalty coefficient. Based on this, it can be said that if the penalty coefficient is selected within certain limits, it does not affect the solution time much.

\subsection{Examination the pheromone update coefficient}

As mentioned before, the value expressing the probability of choosing the values determined for the design variables by the ants is called as the pheromone. In order to achieve the optimum solution, the existing pheromones must be updated in every iteration of the optimization process. The coefficient used for updating pheromones is called the pheromone update coefficient. While the amount of pheromone in the path followed by the best ant is increased by a correlation depending on the pheromone update coefficient, the pheromone amounts in other paths are reduced. As a result, the total amount of pheromones never changes, and is shared according to the likelihood that all routes are preferred.

Seven different values $(0.010,0.015,0.020,0.025,0.030,0.035$ and 0.040$)$ are used to determine the appropriate value of pheromone update coefficient for the optimum design problem of the ten bar truss. A total of 21 optimizations are performed for each pheromone update coefficient value using the colonies consist of 5 to 5000 ants. The penalty coefficient is taken as 3.0 in the optimizations made to examine the pheromone update coefficient.

The change of the penalized objective function, the iteration number and optimization time versus on the pheromone update coefficient are given, respectively, in Figure 6, Figure 7 and Figure 8.

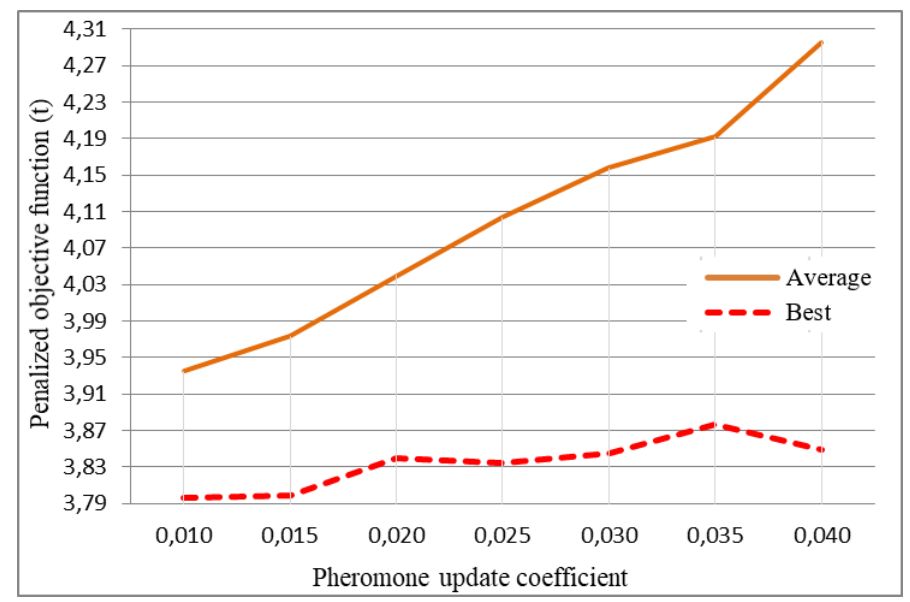

Figure 6. The penalized objective function versus the pheromone update coefficient 


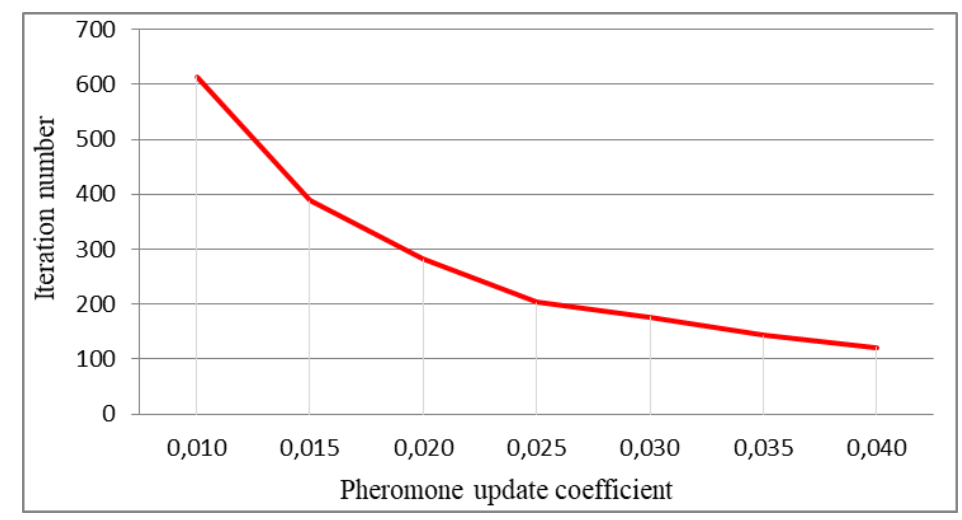

Figure 7. Average of the iteration number versus the pheromone update coefficient

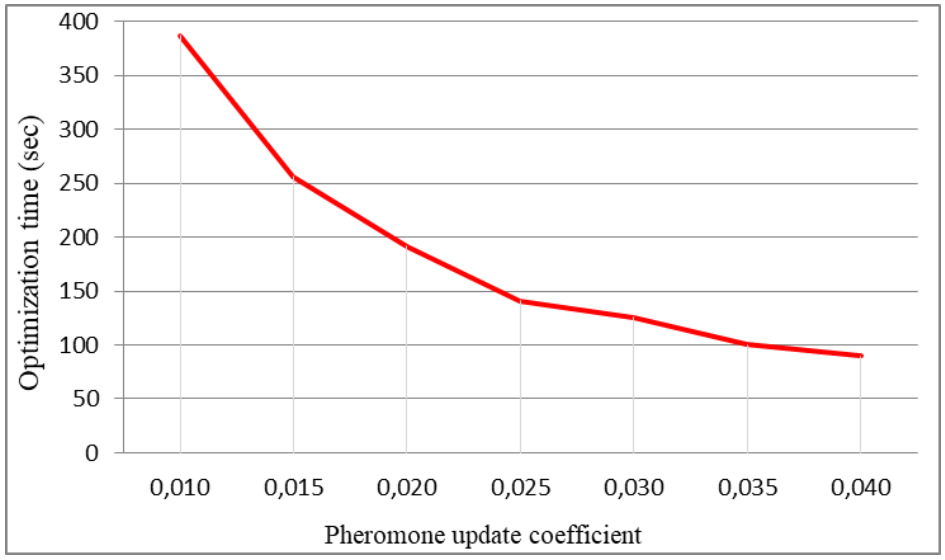

Figure 8. Average of optimization time versus the pheromone update coefficient

It is shown from these figures that the best solution is achieved with 0.01 value of the pheromone update coefficient. Obviously, as the pheromone update coefficient decreases, the best and average value of the penalized objective function decreases. On the other hand, it is also seen that as the pheromone update coefficient increases, the number of iterations and the average value of the optimization time decreases significantly. Therefore, considering the quality of the solutions and the time to reach the solution, an optimum value can be mentioned for the pheromone update coefficient.

\subsection{Examination the size of the values list for design variables}

In this study, optimization is carried out using discrete design variables. The lists containing the possible values of these discrete design variables are determined before optimization process. A list of 200 values (Table 1) was used for design variables in the previous chapters. In this section, lists of different sizes are used to see the effect of the size of the value list determined for the design variables on the optimum solution. For this purpose, the list containing 200 values was simplified and new lists containing 100, 50 and 25 values were created. In this examination, the penalty coefficient is taken as 3.0 and the pheromone update coefficient as 0.010 .

The values of the penalized objective function, the iteration number and optimization time depending on the size of values list for design variables are given, respectively, in Figure 9, Figure 10 and Figure 11. 


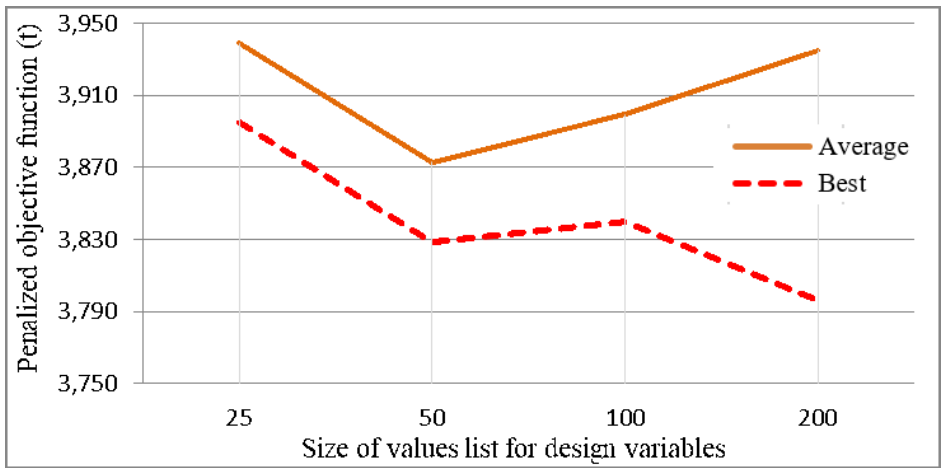

Figure 9. The penalized objective function versus the size of the values list

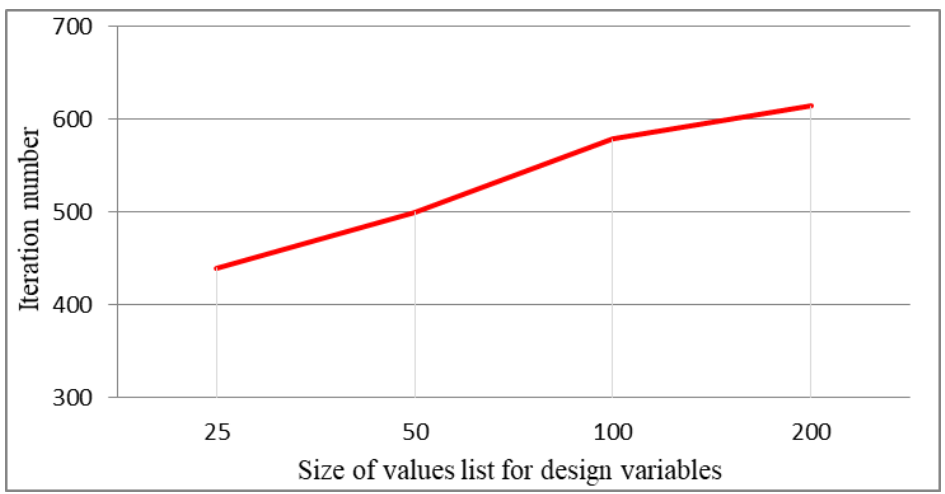

Figure 10. Average of iteration number versus the size of the values list

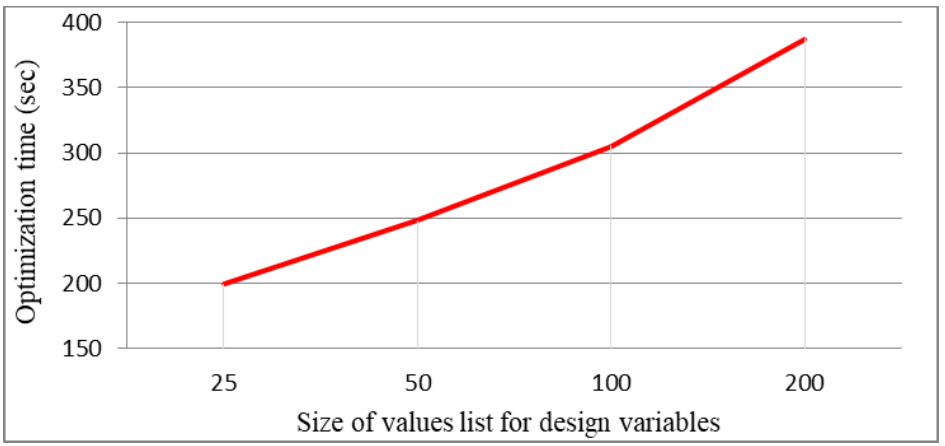

Figure 11. Average of optimization time versus the size of the values list

From this figures, as the design variable set gets wider, the best value of penalized objective function decreases. Keeping the set of design variables wide has the advantage of finding the optimum design, but the mean value of the number of iterations also increases. For the same reason, the optimization time increases significantly. In fact, the main parameter to be considered is the solution time, not the number of iterations. While the solution time may be less in cases where the number of iterations is high, the solution time may increase when the number of iterations is low.

\subsection{Examination the number of ants used}

The effects of the number of ants on solution results were mentioned in previous chapters. In this section, changes in the values of the penalized objective function, the 
iteration number and optimization time versus the number of ants are given in Figure 12, Figure 13 and Figure 14, respectively.

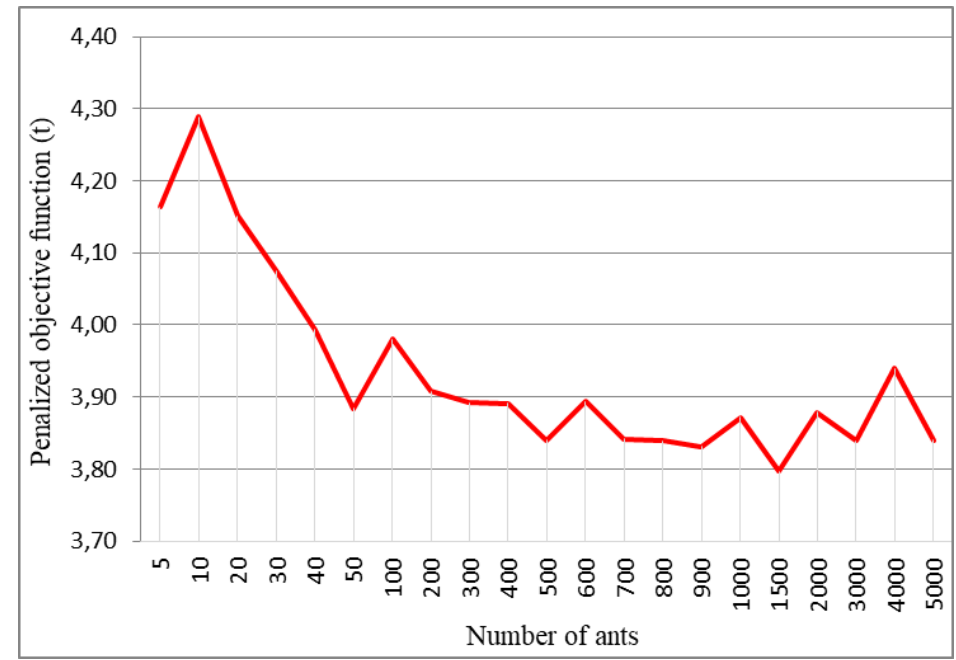

Figure 12. The penalized objective function depending on the number of ants

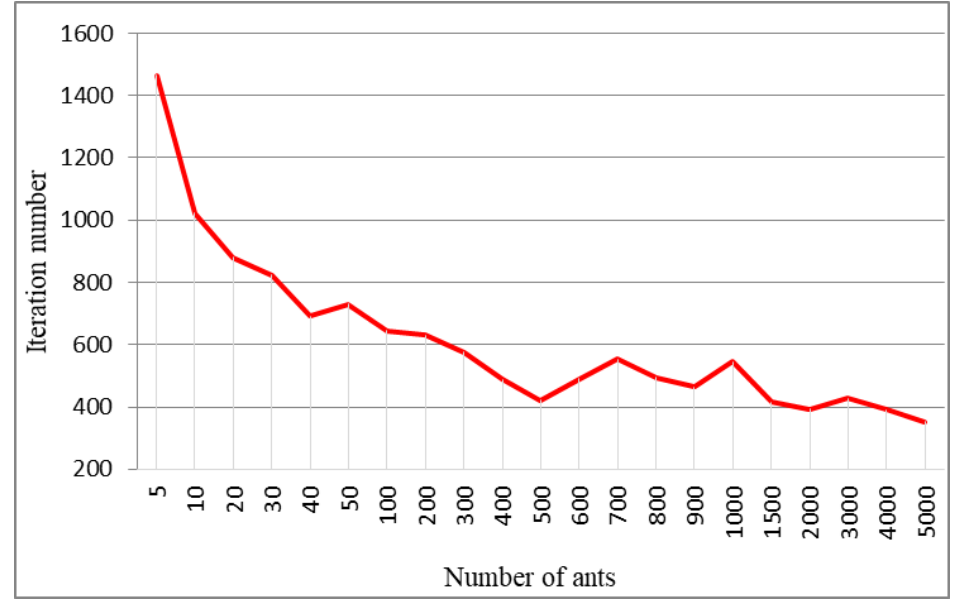

Figure 13. Average of the iteration number depending on the number of ants

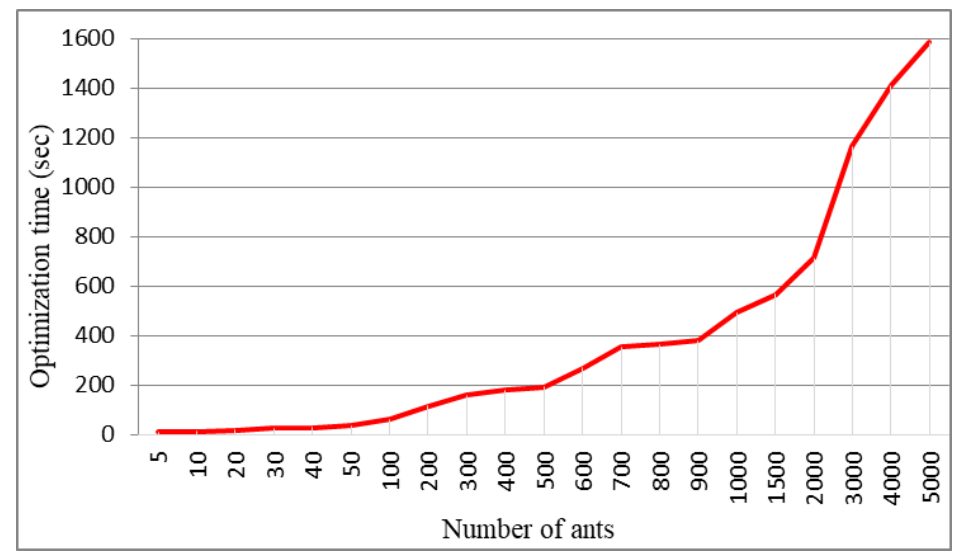

Figure 14. Average of optimization time depending on the number of ants 
The set with the best solutions was found with values of 200 design variables, 3.0 penalty coefficient, and pheromone update coefficient 0.010 . If an evaluation is made based on this, the penalized objective function values of the solutions where the number of ants are chosen very low is found to be high. Although the penalized objective function decreases as the number of ants increases, after a certain point there has not been much change and the curve is horizontal. As expected, the number of iterations tends to decrease as the number of ants increases. However, the optimization time increased very rapidly depending on the increase of the number of ants. Similar to the case of determination the value of pheromone update coefficient, an optimum value can be mentioned also for the number of ants in terms of the quality of the results and the time to reach the optimum result.

\section{Conclusions}

In this study, the optimum design of plane trusses is studied using an ant colony optimization algorithm. The aim of the study is to determine the effect of optimization parameters in the method used on the results. For this purpose, a total of 21 colonies with different numbers of ants (from 5 to 5000) were used, and the penalty coefficient, pheromone update coefficient and the size of the list for values for design variables was investigated. As a result of the study, the following conclusions and suggestions have been achieved:

- The change of the penalty coefficient value does not have a regular effect on the proximity of the solution reached to the optimum value, the number of iterations, and the optimization time. However, based on the example handled in this study, it is seen that the value of the penalty coefficient is important in order to reach the optimum solution.

-Depending on the decrease in the pheromone update coefficient, there is a nonlinear increase in the number of iterations and optimization time, an almost linear decrease in the average and best value of the penalized objective function.

-Depending on the increase in the size of the design variable value set, the number of iterations and optimization time increase linearly, and the best value of the penalized objective function generally decreases. However, the change in the average value of the penalized objective function is uncertain. Thus, although it is important to use a sufficient number of design variable values, it is seen that using more values than necessary may have negative effects on the result.

-Depending on the increase in the number of ants, the value of penalized objective function decreased rapidly at first and then followed a horizontal course, the number of iterations decreased and the optimization time increased nonlinearly. Therefore, it is important to determine the optimum number of ants so that the best solution can be reached in a short time.

In this study, it has been demonstrated once again that the values of the optimization parameters strongly affect the quality of the results and the time required for optimization. Therefore, detailed examination of the optimization parameters conducted in this study should be realized for the other optimization methods in future studies. 


\section{References}

[1] Yılmaz A. H., Düzlem çelik kafes sistemlerin karınca kolonisi yöntemi ile optimum tasarımı, Y. Lisans Tezi, Tekirdağ Namık Kemal Üniversitesi, Fen Bilimleri Enstitüsü, Tekirdă̆, (2019).

[2] Dorigo M., Optimization, Learning and Natural Algorithms, PhD Thesis, Politecnico di Milano, Italy, (1992).

[3] Manuel of Steel Construction - Allowable Steel Design, 9th Ed., American Institute of Steel Construction, Chicago, III, (1989).

[4] Bland, J. A., Optimal structural design by ant colony optimization, Engineering Optimization, 33, 4, 425-443, (2001).

[5] Camp, C. V. and Bichon, B. J., Design of space trusses using ant colony optimization, Journal of structural engineering, 130, 5, 741-751, (2004).

[6] Camp, C. V., Bichon, B. J. and Stovall, S. P., Design of steel frames using ant colony optimization, Journal of Structural Engineering, 131, 3, 369-379, (2005).

[7] Serra, M. and Venini, P., On some applications of ant colony optimization metaheuristic to plane truss optimization, Structural and Multidisciplinary Optimization, 32, 6, 499-506, (2006).

[8] Kaveh, A., Hassani, B., Shojaee, S. and Tavakkoli, S. M., Structural topology optimization using ant colony methodology, Engineering Structures, 30, 9, 2559-2565, (2008).

[9] Aydoğdu İ., Optimum design of 3-D irregular steel frames using ant colony optimization and harmony search algorithms, Ph.D Thesis, Middle East Technical University, Graduate School of Natural and Applied Science, Ankara, (2010).

[10] Yoo, K. S. and Han, S. Y., A modified ant colony optimization algorithm for dynamic topology optimization, Computers \& Structures, 123, 68-78, (2013).

[11] Babaei, M. and Sanaei, E., Multi-objective optimal design of braced frames using hybrid genetic and ant colony optimization, Frontiers of Structural and Civil Engineering, 10, 4, 472-480, (2016).

[12] Kalatjari, V. R. and Talebpour, M. H., An improved ant colony algorithm for the optimization of skeletal structures by the proposed sampling search space method, Periodica Polytechnica Civil Engineering, 61, 2, 232-243, (2017).

[13] Shafei, E. and Shirzad, A., Ant colony optimization for dynamic stability of laminated composite plates, Steel and Composite Structures, 25, 1, 105-116, (2017).

[14] Liu, T., Sun, G., Fang, J., Zhang, J. and Li, Q. Topographical design of stiffener layout for plates against blast loading using a modified ant colony optimization algorithm. Structural and Multidisciplinary Optimization, 59, 335-350, (2019).

[15] Greco, A., Pluchino, A. and Cannizzaro, F. An improved ant colony optimization algorithm and its applications to limit analysis of frame structures. Engineering Optimization, 51, 1867-1883, (2019).

[16] Li, Y. and He, Y., Multi-objective optimization of construction project based on improved ant colony algorithm, Tehnički vjesnik, 27, 1, 184-190, (2020).

[17] Soheili, S., Zoka, H. and Abachizadeh, M. Tuned mass dampers for the drift reduction of structures with soil effects using ant colony optimization. Advances in Structural Engineering, 24, 771-783 (2021). 
[18] Toğan, V. and Daloğlu, A. T., An improved genetic algorithm with initial population strategy and self-adaptive member grouping, Computers \& Structures, 86, 11-12, 1204-1218, (2008).

[19] Li, L. J., Huang, Z. B. and Liu, F., A heuristic particle swarm optimization method for truss structures with discrete variables, Computers \& Structures, 87, 7-8, 435-443, (2009).

[20] Sönmez, M., Discrete optimum design of truss structures using artificial bee colony algorithm, Structural and Multidisciplinary Optimization, 43, 85-97, (2011).

[21] Sadollah, A., Bahreininejad, A., Eskandar, H. and Hamdi, M., Mine blast algorithm for optimization of truss structures with discrete variables, Computers \& Structures, 102, 49-63, (2012).

[22] Dede, T., Application of teaching-learning-based-optimization algorithm for the discrete optimization of truss structures, KSCE Journal of Civil Engineering, 18, 6, 1759-1767, (2014).

[23] Artar, M., A comparative study on optimum design of multi-element truss structures, Steel and Composite Structures, 22, 3, 521-535, (2016).

[24] Artar, M. and Daloglu, A. T., Optimum design of steel space truss towers under seismic effect using Jaya algorithm, Structural Engineering and Mechanics, 71, 1, 1-12, (2019).

[25] Kaveh, A. and Zaerreza, A., Size/layout optimization of truss structures using shuffled shepherd optimization method, Periodica Polytechnica Civil Engineering, 64, 2, 408-421, (2020).

[26] Rajeev, S. and Krishnamoorthy, C. S., Discrete optimization of structures using genetic algorithms, Journal of Structural Engineering, 118, 5, 1233-1250, (1992).

[27] Aydın, Z., Determination the number of ants used in ACO algorithm via grillage optimization, Uludağ University Journal of The Faculty of Engineering, 22, 3, 251-262, (2017). 